\title{
Administración de clases y gestión del conocimiento
}

\author{
Class management and knowledge management
}

\begin{abstract}
Análida Carvajal Monterosa
Doctorante en Ciencias Sociales de la Universidad del Zulia, Maracaibo, Venezuela Maestría en Educación, SUE Caribe, Universidad de Cartagena, Colombia (2009). Especialista en educación para la Docencia, Universidad Antonio Nariño Miembro de la comunidad de Educadores por la Cultura Científica de la OEI (2011 - 2015). Par evaluador de Colciencias y el MEN. Docente Investigadora Escuela Normal Superior del Distrito de Barranquilla(2011 - 2015). analida22@gmail.com
\end{abstract}

\section{Yanyn Rincón Quintero}

Posdoctora en Derechos Humanos (LUZ, 2013); Posdoctora en Gerencia de las Organizaciones (URBE, 2011); Doctora en Ciencias Gerenciales (URBE, 2006), M.Sc. en Administración de Empresas Turísticas: Mención Gerencia Hotelera (LUZ, 2000); Licenciada en Comunicación Social: Mención Publicidad y RRPP. (LUZ, 1993). Docente-Investigadora Universidad Simón Bolivar, Barranquilla, Colombia .ORCIID: http://orcid.org/0000-0003-2427-316.Correo Personal: yanynrincon@gmail.com, yrincon2@unisimonbolivar.edu.co

"Los profesores saben que su trabajo está cambiando, al mismo tiempo que el mundo en el que se desenvuelven. En la medida en que las actuales estructuras y culturas de la enseñanza se dejan tal cual están, la tarea de responder a estos cambios complejos y acelerados desde el aislamiento sólo creará mayores sobrecargas, intensificación, culpabilidad, incertidumbre, cinismo y abandono

pasivo... Las reglas del mundo están cambiando. Es hora de que las reglas de la enseñanza y del trabajo de los docentes varien con ellas". Hargreaves: 1999): Profesorado, cultura y postmodernidad: Cambian los tiempos, cambia el profesorado.

Madrid: Morata. P. 289).

Para citar este artículo: Carvajal A., RincónY. (2017). Administración de clases y gestión del conocimiento. Escenarios, 15(1), pp. 109-118. Doi: http:/ / dx.doi.org/10.15665/esc.v15i1.1124

Recibido: enero 17 de 2017

Aceptado: febrero 20 de 2017

\section{RESUMEN}

El presente artículo está vinculado al proyecto de tesis doctoral Pensamiento Crítico con el uso de las TIC para la comprensión y producción de textos, del programa Doctorado en ciencias Sociales de la Universidad del Zulia. A través de un enfoque cualitativo se aborda la investigación acción participativa para determinar consensos sobre la administración de la clase en la gestión del conocimiento, explorando conceptos de una manera eficiente a través de las actividades propuestas en el evento pedagógico. Se propone determinar la manera de planificación de las clases de los docentes del Programa de Formación Complementaria (PFC) de la Escuela Normal Superior del Distrito de Barranquilla (ENSDB) para almacenar, recuperar y distribuir la información en la gestión del conocimiento de los estudiantes; combinando los recursos de la tecnología para la solución de posibles problemas (ayudar a la construcción de conocimiento). Esta investigación genera espacios de reflexión pedagógica acerca de la administración o planificación de la clase en cualquier saber disciplinar; estableciendo un entorno formativo diferente. Se basa en las teorías de: Peter Senge 
(1994) del aprendizaje continuo; la visión cognitiva de Beltrand (1999); el desarrollo consistente y la introducción de nuevos productos que valoren los clientes es un importante factor para la prosperidad y crecimiento de una organización de Domínguez Machucha (2009); modelo circular en el que los objetivos se sitúan en el centro, influyendo y recibiendo influencia de todo lo que ocurre durante la preparación y presentación de la clase de George y Cowan (1999)

Palabras Clave: Administración de la clase, Gestión del conocimiento, Estrategias didácticas.

\begin{abstract}
Through the following qualitative research is approached from a participatory action research approach, administration of the class in knowledge management; accessing information and exploring concepts efficiently through the activities proposed in the educational event. It is proposed to determine the lesson plans of teachers in the Outreach Program (PFC) in Higher Normal School District of Barranquilla (ENSDB) to store, retrieve and distribute information on the management of knowledge of students; ie, managing the class combining technology resources for solving possible problems (help build knowledge). This research will generate spaces for educational thinking about managing or planning class at any disciplinary knowledge; establishing a different learning environment. It is based on the theories of Peter Senge (1994) of lifelong learning; Beltrand (1999) cognitive vision; consistent development and introduction of new products valued customers is an important factor for the prosperity and growth of an organization Dominguez Machucha (2009); circular pattern in which the goals are placed in the center, influencing and receiving influence of everything that happens during the preparation and presentation of the class of George and Cowan (1999).
\end{abstract}

Keywords: Business Class, Knowledge Management, Teaching Strategies.

\section{INTRODUCCIÓN}

La transformación de la gestión de la escuela para mejorar el aprovechamiento y desarrollo de habilidades y comunicación basándose en la gestión del conocimiento, es un tema, por demás importante, para tener en cuenta por los docentes de cualquier disciplina o institución educativa, siempre y cuando estén dispuestos a hacer frente a los cambios permanentes de la sociedad, mediante el desarrollo de nuevas estrategias y métodos sistemáticos que lleven a los estudiantes a la gestión del conocimiento.

Los docentes del Programa de Formación Complementaria (PFC) de la Escuela Normal Superior del Distrito de Barranquilla (ENSDB) requieren una nueva forma de administrar la clase para que los estudiantes puedan adquirir habili- dades que le permitan incorporarse a su medio social sin déficits formativos. Para esta transformación la incorporación de la competencia en la administración de la clase es una respuesta obligada a las nuevas formas de generar, crear y acumular conocimiento, basado en la investigación y la docencia.

En el acercamiento práctico a la administración de la clase se hace necesaria la creación de nuevas orientaciones, nuevos modelos, lo cual lleva a los estudiantes a ser capaces de desarrollar habilidades en el manejo de las TIC, de mejorar procesos como: la obtención de la información, el análisis, la síntesis, la conceptualización, el pensamiento sistémico, el pensamiento crítico, la investigación y la metacognición, convirtiéndoles en generadores de conocimientos. 
La realidad vigente es que las clases del PFC de la ENSDB se deben transformar porque en la sociedad del conocimiento el modo de transmitir la información, el modo de comunicarse, el modo de enseñar a aprender, donde la información de calidad está organizada, estructurada de manera que acentúa los cambios del rol futuro del profesor -no será de éste como un transmisor de conocimientos- y el estudiante no será un simple receptor de esos conocimientos-.

Partiendo de lo anterior se llegó al siguiente cuestionamiento: ¿Cómo planifican la clase los docentes del PFC de la ENSDB?

\section{Marco Referencial}

¿Planificación De La Clase? En la era de la sociedad de la información, el mundo ha evolucionado más rápidamente que la capacidad de transformación de la escuela, que no solamente significa ponerse al día sino prepararse para adelantar los cambios, creando conocimiento y para ello se requiere el aprender a aprender.

La capacidad de administrar la clase por parte del docente es factor clave para la obtención del conocimiento; en este sentido y citando a Senge (1994) se enumeran las cinco disciplinas del aprendizaje continuo, a saber:

\section{Tabla 1}

\begin{tabular}{|c|c|c|c|c|}
\hline $\begin{array}{c}\text { Desarrollar la } \\
\text { maestría personal }\end{array}$ & $\begin{array}{c}\text { Identificar y } \\
\text { desarrollar los } \\
\text { modelos mentales }\end{array}$ & $\begin{array}{l}\text { Impulsar la visión } \\
\text { compartida }\end{array}$ & $\begin{array}{l}\text { Fomentar el trabajo } \\
\text { en equipo }\end{array}$ & $\begin{array}{l}\text { Generar el } \\
\text { pensamiento } \\
\text { sistémico }\end{array}$ \\
\hline $\begin{array}{l}\text { El docente reconoce } \\
\text { sus verdaderas } \\
\text { capacidades, } \\
\text { propone soluciones. }\end{array}$ & $\begin{array}{l}\text { El docente debe } \\
\text { conocer a fondo el } \\
\text { modelo Pedagógico } \\
\text { de la Institución } \\
\text { y compararlo con } \\
\text { otros modelos } \\
\text { pedagógicos. }\end{array}$ & $\begin{array}{l}\text { El sello institucional } \\
\text { se manifiesta por } \\
\text { el conocimiento } \\
\text { y aplicación de la } \\
\text { visión de la Escuela. }\end{array}$ & $\begin{array}{c}\text { El docente debe } \\
\text { compartir la } \\
\text { información con sus } \\
\text { pares y estudiantes } \\
\text { de las estrategias } \\
\text { empleadas en la } \\
\text { clase }\end{array}$ & $\begin{array}{l}\text { El docente comparte } \\
\text { información con sus } \\
\text { pares y estudiantes } \\
\text { en forma colaborativa } \\
\text { y cooperativa }\end{array}$ \\
\hline
\end{tabular}

Fuente: Construcción autores (2016)

1) Desarrollar la maestría personal (Dominio Personal): Para conocer quién es, qué quiere y qué es capaz de hacer la escuela, el docente debe aprender a reconocer sus verdaderas capacidades y la de quienes lo rodean. Asimismo, debe identificarse con la visión de la organización, proponer soluciones creativas y aceptar el compromiso de crecer conjuntamente con la institución.

2) Identificar y desarrollar los modelos mentales: Los paradigmas o modelos inconscientes restringen la visión de lo que rodea a la organización educativa. El manejo adecuado de parte de los docentes, de los modelos le permitirán una comunicación sin ruidos y más efectiva dentro de la escuela.

3) Impulsar la visión compartida: Todas las visiones personales deben estar en conjunción con la visión de la institución educativa. Cuando esto se logra, dicha visión se convierte en una inmensa fuente de inspiración y productividad, y les brinda a los miembros de la comunidad educativa el impulso necesario para convertirla en una institución con educación de calidad.

4) Fomentar el trabajo en equipo: Tener las habilidades necesarias para colaborar, trabajar en equipo y compartir información. El conjunto de estrategias que se utilicen para maximizar los buenos resultados y minimizar las pérdidas académicas logrando evitar la pérdida de tiempo e información en beneficio de los objetivos organizacionales y así motivar la participación activa de todos los estamentos de la institución escolar donde todos participan del proyecto escolar, trabajan, colaboran y se ayudan para gestionar el conocimiento.

5) Generar el pensamiento sistémico: La quinta disciplina promueve la construcción y re- 
construcción del conocimiento a través del trabajo colaborativo y cooperativo, la creatividad y la experimentación; elementos claves a tener en cuenta por todo docente en la planificación del proceso de enseñanza aprendizaje.

También Beltrand (1999), desde una visión cognitiva, define el aprendizaje como "un cambio más o menos permanente de conducta que se produce como resultado de una práctica" (p. 15) para la adquisición de conocimiento y la construcción de significado y cuyos rasgos definidores son el ser complejo, cognitivo, estratégico y significativo. Entre los elementos del aprendizaje señala el procesador, los contenidos, los procesos y las estrategias.

Según Domínguez (1995, p.103): “El desarrollo consistente y la introducción de nuevos productos que valoren los clientes es un importante factor para la prosperidad y crecimiento de una organización". No es posible planificar un nuevo curso sin tener información básica sobre el perfil de los estudiantes y sus necesidades potenciales. La institución educativa, inserta cada vez más en un entorno altamente competitivo, necesita diseños excelentes para prosperar.

Una vez conocido el perfil del estudiante, el docente debe aplicar un modelo de desarrollo curricular para responder a las clásicas preguntas: a) ¿Qué enseñar, por qué y para qué? (objetivos), b) ¿Cómo enseñar? (metodología, estrategias, recursos), y c) ¿Qué evaluar, cómo, cuándo y para qué? (retroalimentación).

El modelo de desarrollo curricular tradicional tiene una secuencia lineal que se inicia con la fijación de objetivos y resultados. A partir de ahí, se seleccionan los métodos educativos y se prepara el plan de enseñanza para su aplicación. Durante esta etapa de ejecución tiene lugar el aprendizaje del alumno, que, salvo en procesos de evaluación continua, se valora después. Finalmente, se busca la retroalimentación del estudiante con la finalidad de evaluar y revisar el curso. Y el ciclo vuelve a empezar.

Fig 1 .Ciclo del modelo

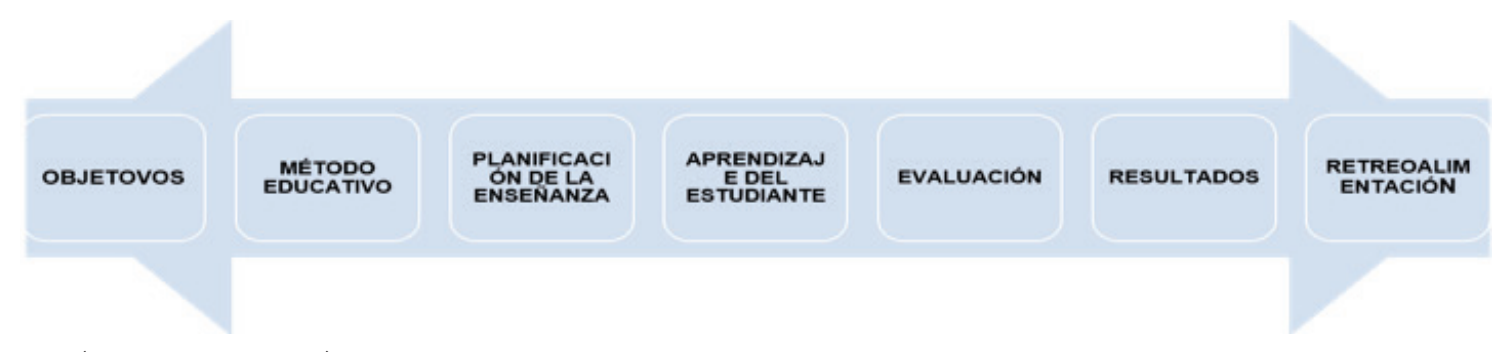

Fuente: (Carvajal, 2016)

Los investigadores conceptúan que esta secuencia lineal presenta ciertos inconvenientes: a) Asume que los objetivos y los resultados sólo se consideran al principio del proceso. b) Se concentra en la enseñanza más que en el aprendizaje.

Para resolver la mayor parte de los problemas señalados, George y Cowan (1999) desarrollan un modelo circular en el que los objetivos se sitúan en el centro, influyendo y recibiendo influencia de todo lo que ocurre durante la preparación y presentación de la clase.
El primer elemento que hay que tener en cuenta en este modelo es la valoración, por su influencia en el proceso de aprendizaje y por ser un determinante clave de los resultados finales del proceso de enseñanza-aprendizaje. El aprendizaje es una respuesta de los objetivos y resultados perseguidos, así como de la valoración. Objetivos, resultados y valoración ofrecen un mensaje similar al receptor, el estudiante.

La formación o proceso de enseñanza se diseña, a partir de aquí, según las necesidades de los estudiantes que luchan por conseguir los objetivos que se valoran. Estilos de aprendizaje, 
estrategias y necesidades influyen en la formación.

La evaluación, condicionada directamente por los objetivos, constituye un proceso de recolección de datos a realizar durante y después del proceso de enseñanza-aprendizaje, que deben ser analizados y forman la base sobre la que tomar decisiones, que incluyen, por ejemplo, cambios en los objetivos o en las estrategias.

Siguiendo este modelo, una buena administración de la clase pasaría por entender cómo fijar los objetivos de la materia a enseñar, entender cómo aprenden los alumnos, establecer un buen plan formativo $\mathrm{y}$, finalmente, recabar la información adecuada para la valoración del proceso y la posterior toma de decisiones; es decir realizar un diseño preliminar del curso estableciendo módulos formativos potenciales con los que construir el programa de la asignatura.

Lo hasta aquí expuesto, se tendría el proceso lógico en el diseño curricular al que le faltaría una pieza clave: información sobre el estudiante. De esta forma, a las preguntas iniciales habría que añadir una más: ¿a quién se va a enseñar? En este caso, y para evitar diseñar sin conocer el perfil del alumno, se debe diseñar un curso con una metodología flexible, abierto a modificaciones que permitieran adaptar las enseñanzas al alumno una vez conocido su perfil. Y para conocer hay que preguntar o, aplicando terminología de gestión empresarial, investigar el mercado.

Ahora bien, Moursund (1999) expone que uno de los principales objetivos de la educación, es enseñar a los estudiantes a resolver problemas complejos y a acometer tareas difíciles. Los estudiantes necesitan recibir instrucciones y realizar prácticas muy completas, para trabajar adecuadamente en el entorno de la generación de conocimientos.

Es así como los investigadores teniendo en cuenta lo expuesto pos Senge (1994); consideran que se deben tener en cuenta los siguientes aspectos para la administración de una clase:
1. Desarrollar competencia. Para los docentes el objetivo es aumentar el conocimiento y habilidad en una disciplina o en un área del contenido multidisciplinario. Debe ser frecuente que en una actividad (clase), el estudiante alcanza un nivel de habilidad elevado en el área específica que está estudiando construyendo conocimiento.

2. Mejorar las habilidades de investigación. El administrar adecuadamente una clase requiere la utilización de aptitudes para investigar y ayuda a que estas se desarrollen.

3. Incrementar las capacidades mentales de orden superior, capacidad de análisis y de síntesis. Esto se logra cuando la organización de la clase es retador y está enfocado a que los estudiantes desarrollen las habilidades antes mencionadas.

4. Participar en un proyecto. El proyecto ayuda a que los estudiantes incrementen su conocimiento y habilidad para emprender una tarea desafiante que requiera un esfuerzo sostenido durante un período de tiempo considerable. Usualmente un grupo de estudiantes trabaja en un proyecto, de esta manera aprenden a asumir responsabilidad en forma individual y colectiva para que el equipo complete con éxito la tarea. Los estudiantes aprenden los unos de los otros.

5. Aprender a usar las TIC. Los estudiantes incrementan el conocimiento y la habilidad que tienen en las TIC a medida que trabajan en la clase. Las actividades se diseñan con el objetivo específico de alentar en los estudiantes la adquisición de nuevas habilidades y conocimientos en las tecnologías.

6. Aprender a autoevaluarse y a evaluar a los demás. Los estudiantes incrementan su habilidad de autoevaluación responsabilizándose por su propio trabajo y desempeño. Aprenden también, a evaluar el trabajo y desempeño de sus compañeros y a darles retroalimentación.

7. Desarrollar un portafolio. La administración de la clase requiere que los estudiantes rea- 
licen un producto, una presentación de alta calidad. El proyecto es parte del portafolio del estudiante en el proceso académico.

8. Comprometerse en un proyecto. Los estudiantes se comprometen activa y adecuadamente a realizar el trabajo del proyecto, por lo que se encuentran internamente motivados. Esta es una meta del proceso. El profesor realiza observaciones diarias que le permiten establecer si el estudiante está comprometido con la tarea, si muestra una colaboración ejemplar o indisciplina. También solicita a sus estudiantes que lleven un diario en el que hagan anotaciones sobre su trabajo específico y sus contribuciones al proyecto del grupo, pidiéndoles que se lo presenten una vez al mes por lo menos.

9. Ser parte de una comunidad académica. Toda la clase - los estudiantes, el maestro - se convierten en una comunidad académica, en la que se trabaja cooperativamente aprendiendo unos de otros. Esta comunidad académica a menudo se expande para incluir padres, estudiantes de otras clases y otras personas.

10. Trabajar en ideas que son importantes. Las clases se enfocan en ideas que son importantes; en temas que tienen continuidad y que son relevantes para el profesor, el colegio o para los mismos estudiantes en su práctica pedagógica investigativa. Por ejemplo, comunicación, competencias y solución de problemas en forma interdisciplinaria, son las metas de los trabajos presentados por los estudiantes.

El docente debe propender por una clase centrada en el aprendizaje. Por este motivo, los estudiantes tienen un peso significativo en la selección de las áreas de contenido y en la escogencia de los temas que van a desarrollar. El maestro debe asegurarse que los estudiantes entienden lo que están haciendo, por qué es importante y cómo los van a evaluar. Es más, los estudiantes deben ayudar a establecer algunos de los objetivos en los que van a ser evaluados y el método de evaluación que se va a usar.
Fig. 2 fotografía de aspectos de ambientes de Escuela Normal Superior del Distrito de Barranquilla

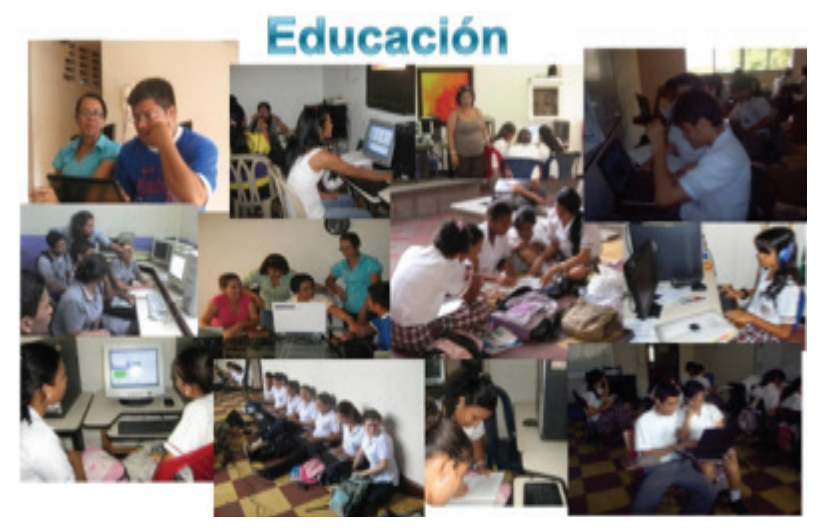

Estudiantes y docentes de la Escuela Normal Superior del Distrito de Barranquilla en las aulas de clase Fuente: Los autores

Estas características de la clase, de centrarse en el aprendizaje, contribuyen a que el alumno se motive y se comprometan activamente. Se requiere un alto nivel de motivación interna y de compromiso para que ésta sea exitosa.

La clase se orienta hacia el problema o la actividad. Ver Fig.2 En términos muy simples, la educación se preocupa mucho por ayudar a los estudiantes en: a) adquirir conocimientos y habilidades básicas y b) aprender a resolver problemas complicados y llevar a cabo actividades difíciles utilizando estos conocimientos y habilidades. Los términos de orden elemental y orden superior se aplican con frecuencia al conocimiento y a las habilidades que son básicas para alcanzar estos dos objetivos educativos.

Según Moursund (1999), ambos tipos de conocimientos y habilidades son esenciales para que una persona se considere educada. Esto quiere decir, que los conocimientos y habilidades de orden elemental deben adquirirse en el contexto de la solución de problemas y la realización de tareas actividades ambos retadores. En algunas actividades de la clase, una de las metas principales es que el estudiante trabaje en la solución de un problema complejo o en la realización de una actividad que también lo es. Cada lección debe enfatizar el conocimiento y las actividades de orden superior. 
La evaluación auténtica es un componente importante en el desarrollo de la clase. Los estudiantes necesitan tener un entendimiento claro de las metas, los objetivos y la evaluación de los temas a desarrollar. El aprendizaje de estos elementos constituye parte importante de entender cómo se emprenden (acometen) las actividades.

Es importante hacer la distinción entre retroalimentación (evaluación formativa) y valoración (evaluación sumativa). Durante el proceso de la clase los estudiantes pueden recibir evaluación formativa (retroalimentación), de ellos mismos, de sus compañeros, de sus maestros y de otras fuentes. Esta retroalimentación ayuda al estudiante a comprender cómo se realizan un producto final, una presentación o una representación de buena calidad.

Al estudiante, se le evalúa tanto por el desarrollo del proceso como por el producto final. No se debe olvidar que un buen ambiente de aprendizaje permite al estudiante experimentar, esto es, ensayar cosas que pueden no dar buen resultado. Se le estimula y premia por esa conducta de ensayo y error.

En otras palabras, los estudiantes a la vez que construyen el conocimiento; eligen los diferentes textos, gráficos, vocabulario; van planeando lo que van a desarrollar, van realizando búsquedas y responsabilidades de tareas, participan todos y cada uno de ellos, pero cada cual tiene la posibilidad de elegir aquella que le es más a fin de sus intereses y capacidades.

El docente hace un seguimiento permanente a los estudiantes para observar su desenvolvimiento y ofrecerles diferentes posibilidades que les permitan desarrollarse armónicamente y no sólo beneficiando determinados aspectos. Se busca que los estudiantes se conozcan un poco más a sí mismos y vean en ellos la facultad para elabora recursos que permitan un aprendizaje significativo; se interesen por investigar para buscar los puntos de interés e inicien y/o continúen su producción.

La investigación en la clase no es otra cosa que la posibilidad de explorar, observar, discutir, indagar y preguntar al docente, a los padres o hermanos, vecinos o familiares, sobre sus inquietudes e intereses para construir conocimiento y acciones que le permitan crear bajo su propio criterio (Christensen, 1991).

Desde el problema planteado se propone administrar la clase combinando los recursos de la tecnología para la solución de posibles problemas (ayudar a la construcción de conocimiento). Se propician situaciones, aquí es cuando los estudiantes, producto de su propio desarrollo cognitivo y motivación, descubren por sí mismos las diferentes variantes de solución a partir de un análisis lógico del entorno de la clase, la aplicación que se está realizando y el objetivo de la actividad docente que está teniendo lugar.

El reto educativo está en aprovechar una buena planificación de la clase para lograr el despojo de concepciones y prácticas anquilosadas y fracasadas, y así dar paso a nuevos ambientes y entornos de enseñanza aprendizaje que posibiliten la construcción de mundos múltiples, reales o imaginarios, en donde sea posible el pensamiento creativo y la realización personal.

\section{Metodología}

Esta investigación cualitativa se plantea en el enfoque de una investigación acción participativa, basada en la administración de la clase. En lo que respecta el método se trata de acceder a la información y explorar conceptos de una manera eficiente a través de las actividades propuestas en el evento pedagógico.

Es acción participativa porque desde una perspectiva constructivista facilita que el estudiante se convierta en "un procesador activo y constructor de su conocimiento" (Piaget, 1977), en función de sus intereses y dominio de conocimientos y habilidades previas sobre la temática para que el aprendizaje se produzca de forma significativa; utilizando la terminología propuesta en su momento por Ausubel.

La creación de entornos más rico desde una perspectiva semiológica, en los cuales, los alumnos podrán comprender e interaccionar 
con la información, en función de diversos sistemas simbólicos utilizados y seleccionar el que considere más oportuno a sus necesidades.

Es así como el estudiante es un ser activo que construye su conocimiento sobre la realidad interactuando con ésta (Piaget, 1977).

Para ésta se tomó una muestra correspondien- te de 8 docentes del Programa de Formación Complementaria de la Escuela Normal Superior del Distrito de Barranquilla (ENSDB).

$\mathrm{Al}$ analizar los resultados de la encuesta realizada a los docentes del Programa de Formación Complementaria (PFC) de la Escuela Normal Superior del Distrito de Barranquilla se puede observar:

\section{Cuadro 1}

\section{ENCUESTA A DOCENTES DEL PFC DE LA ENSDB}

\begin{tabular}{|c|c|c|c|c|c|c|c|}
\hline No & AFIRMACIÓN & SI & $\%$ & NO & $\%$ & $\begin{array}{l}\text { DOCENTE: } \\
\text { ESTRATEGIAS } \\
\text { QUE UTILIZO }\end{array}$ & $\begin{array}{l}\text { ANÁLISIS DE LA } \\
\text { INVESTIGADORA }\end{array}$ \\
\hline 1 & $\begin{array}{l}\text { Los estudiantes compar- } \\
\text { ten diferentes clases de } \\
\text { textos de un mismo tema. }\end{array}$ & 4 & 50,0 & 3 & 37,5 & $\begin{array}{l}\text { Se les entregan los } \\
\text { textos de los temas y } \\
\text { a veces comentan lo } \\
\text { leído e investigado }\end{array}$ & $\begin{array}{l}\text { Se observa que los docentes muy } \\
\text { poco utilizan las diferentes clases } \\
\text { de textos para trabajar en clase. }\end{array}$ \\
\hline 2 & $\begin{array}{l}\text { Hay trabajo colaborativo } \\
\text { con las lecturas de los } \\
\text { textos. }\end{array}$ & 5 & 62,5 & 3 & 37,5 & $\begin{array}{l}\text { Los estudiantes com- } \\
\text { parten la información } \\
\text { entre ellos. }\end{array}$ & $\begin{array}{l}\text { Los docentes poco propician el } \\
\text { trabajo colaborativo con la lectura } \\
\text { de los temas de cada disciplina. }\end{array}$ \\
\hline 3 & $\begin{array}{l}\text { Hay conclusiones indi- } \\
\text { viduales acerca de lo } \\
\text { socializado y trabajado } \\
\text { colectivamente. }\end{array}$ & 4 & 50,0 & 4 & 50,0 & $\begin{array}{l}\text { Se socializa algunas } \\
\text { veces lo leído por } \\
\text { los estudiantes, sólo } \\
\text { cuando exponen. }\end{array}$ & $\begin{array}{l}\text { Los estudiantes y profesores a ve- } \\
\text { ces llegan a conclusiones concer- } \\
\text { tadas o individuales acerca de los } \\
\text { temas investigados. }\end{array}$ \\
\hline 4 & $\begin{array}{l}\text { Los estudiantes siguen } \\
\text { una guía entregada por } \\
\text { el profesor }\end{array}$ & 2 & 25,0 & 6 & 75,0 & $\begin{array}{l}\text { Muy pocas veces } \\
\text { entrego una guía. A } \\
\text { veces les entrego } \\
\text { instrucciones a los } \\
\text { estudiantes. }\end{array}$ & $\begin{array}{l}\text { Los docentes no son dados a pre- } \\
\text { sentar una guía de lectura o inves- } \\
\text { tigación acerca de un tema. }\end{array}$ \\
\hline 5 & $\begin{array}{l}\text { Los estudiantes se orga- } \\
\text { nizan ellos en grupos. }\end{array}$ & 6 & 75,0 & 2 & 25,0 & $\begin{array}{l}\text { Los estudiantes son } \\
\text { los que se organi- } \\
\text { zan en grupo. Los } \\
\text { estudiantes sugieren } \\
\text { siempre trabajar en } \\
\text { grupos. }\end{array}$ & $\begin{array}{l}\text { Los docentes poco organizan gru- } \\
\text { pos de estudiantes para el desa- } \\
\text { rrollo de un tema. Los estudiantes } \\
\text { siempre son los que sugieren este } \\
\text { tipo de actividad. }\end{array}$ \\
\hline 6 & $\begin{array}{l}\text { Los estudiantes utilizan } \\
\text { las TIC para la produc- } \\
\text { ción y aplicación del co- } \\
\text { nocimiento. }\end{array}$ & 6 & 75,0 & 2 & 25,0 & $\begin{array}{l}\text { Los estudiantes pre- } \\
\text { sentan sus trabajos a } \\
\text { computador, utilizan } \\
\text { la multimedia, pero } \\
\text { es por iniciativa de } \\
\text { ellos. }\end{array}$ & $\begin{array}{l}\text { Aunque los estudiantes utilizan las } \\
\text { TIC para la producción y aplica- } \\
\text { ción del conocimiento, se observa } \\
\text { por la respuesta de los docentes } \\
\text { que es por iniciativa de los alum- } \\
\text { nos, más no estrategia utilizada } \\
\text { por el docente. }\end{array}$ \\
\hline 7 & $\begin{array}{l}\text { Los estudiantes utilizan } \\
\text { las TIC para almacenar, } \\
\text { recuperar y distribuir la } \\
\text { información de los textos } \\
\text { que leen en clase }\end{array}$ & 3 & 37,5 & 5 & 62,5 & $\begin{array}{l}\text { Los estudiantes traen } \\
\text { información tomada } \\
\text { y copiada de internet. }\end{array}$ & $\begin{array}{l}\text { Los estudiantes no saben, no co- } \\
\text { nocen cómo almacenar, recuperar } \\
\text { y distribuir la información de los } \\
\text { temas vistos en clase a través del } \\
\text { uso de las TIC. }\end{array}$ \\
\hline
\end{tabular}




\begin{tabular}{|c|c|c|c|c|c|c|c|}
\hline 8 & $\begin{array}{l}\text { Los estudiantes presen- } \\
\text { tan en la clase resultados } \\
\text { escritos de sus investiga- } \\
\text { ciones y los socializan. }\end{array}$ & 5 & 62,5 & 3 & 37,5 & $\begin{array}{l}\text { Los trabajos que } \\
\text { presentan los estu- } \\
\text { diantes en clase son } \\
\text { copiados (Copiar y } \\
\text { pegar de internet) o } \\
\text { tomados igual como } \\
\text { viene en los libros }\end{array}$ & $\begin{array}{l}\text { El docente se preocupa de la pro- } \\
\text { ducción de los trabajos de los es- } \\
\text { tudiantes, pero el análisis muestra } \\
\text { que sólo se limitan a la entrega del } \\
\text { trabajo sin indicar pautas o una } \\
\text { guía para construir los textos. }\end{array}$ \\
\hline 9 & $\begin{array}{l}\text { Los estudiantes siempre } \\
\text { procuran la mejora del } \\
\text { desempeño en la clase. }\end{array}$ & 3 & 37,5 & 6 & 75,0 & $\begin{array}{l}\text { Los estudiantes du- } \\
\text { rante la clase no par- } \\
\text { ticipan. }\end{array}$ & $\begin{array}{l}\text { La participación de los estudiantes } \\
\text { es escasa por la falta de investiga- } \\
\text { ción con anticipación de los temas. }\end{array}$ \\
\hline 10 & $\begin{array}{l}\text { Los estudiantes siempre } \\
\text { procuran el logro de re- } \\
\text { sultados en la clase. }\end{array}$ & 5 & 62,5 & 3 & 37,5 & $\begin{array}{l}\text { Hay estudiantes ex- } \\
\text { celentes. Sus notas } \\
\text { son altas. }\end{array}$ & $\begin{array}{l}\text { El docente se preocupa por las } \\
\text { notas obtenidas por el estudiante, } \\
\text { más no por la forma de adquirir la } \\
\text { información para aplicarla. }\end{array}$ \\
\hline 11 & $\begin{array}{l}\text { Guía a los estudiantes a } \\
\text { que lean los textos de su } \\
\text { disciplina, para que los } \\
\text { conozca. }\end{array}$ & 6 & 75,0 & 2 & 25,0 & $\begin{array}{l}\text { A los estudiantes no } \\
\text { les gusta leer. }\end{array}$ & $\begin{array}{l}\text { Muy poco el docente incentiva a } \\
\text { los estudiantes a la búsqueda de } \\
\text { la información en su disciplina. }\end{array}$ \\
\hline 12 & $\begin{array}{l}\text { Guía a los estudiantes a } \\
\text { que lean los textos de su } \\
\text { disciplina, para que los } \\
\text { apliquen en contexto. }\end{array}$ & 6 & 75,0 & 2 & 25,0 & $\begin{array}{l}\text { Credibilidad. Com- } \\
\text { probar lo entendido. } \\
\text { Con ejemplos pro- } \\
\text { pios o de estudian- } \\
\text { tes. }\end{array}$ & $\begin{array}{l}\text { Se observa organización previa de } \\
\text { guías para la lectura de los textos } \\
\text { a desarrollar en clase. }\end{array}$ \\
\hline 13 & $\begin{array}{l}\text { Guía a los estudiantes a } \\
\text { que lean sólo los textos } \\
\text { de su disciplina. }\end{array}$ & 1 & 12,5 & 7 & 87,5 & $\begin{array}{l}\text { Algunas veces tienen } \\
\text { claridad. No se hace } \\
\text { mucho énfasis en } \\
\text { este aspecto. }\end{array}$ & $\begin{array}{l}\text { Los docentes escasamente utili- } \\
\text { zan la lectura de textos de su dis- } \\
\text { ciplina. }\end{array}$ \\
\hline 14 & $\begin{array}{l}\text { Los estudiantes respon- } \\
\text { den las evaluaciones de } \\
\text { su clase en forma mecá- } \\
\text { nica (Conocimiento Táci- } \\
\text { to). }\end{array}$ & 2 & 25,0 & 6 & 75,0 & $\begin{array}{l}\text { Algunas veces lo ha- } \\
\text { cen correctamente. }\end{array}$ & $\begin{array}{l}\text { La mayoría de las veces el estu- } \\
\text { diante responde en forma mecáni- } \\
\text { ca a la evaluación por la forma en } \\
\text { que están diseñadas. }\end{array}$ \\
\hline 15 & $\begin{array}{l}\text { Los estudiantes son } \\
\text { conscientes de las res- } \\
\text { puestas en las evaluacio- } \\
\text { nes de su clase (Conoci- } \\
\text { miento Implícito). }\end{array}$ & 5 & 62,5 & 3 & 37,5 & $\begin{array}{l}\text { Algunas veces lo ha- } \\
\text { cen correctamente, } \\
\text { cuando se le exige } \\
\text { argumentación no } \\
\text { saben cómo hacerlo. }\end{array}$ & $\begin{array}{l}\text { El estudiante a veces no sabe ar- } \\
\text { gumentar el porqué de la respues- } \\
\text { ta a una evaluación. }\end{array}$ \\
\hline & & 63 & & 57 & & & \\
\hline
\end{tabular}

Fuente: Construcción autores(2015)

OBJETIVO: Determinar la planificación de las clases de los docentes del FC de la ENSDB para almacenar, recuperar y distribuir la información en la gestión del conocimiento de los estudiantes.

Los resultados de la encuesta ponen de manifiesto, entre los docentes, el escaso número de estrategias pensamiento crítico con el uso de las TIC para desarrollar la comprensión y producción de textos y construir conocimiento en cualquier disciplina.

Los resultados, en general, muestran que las estrategias de comprensión y producción de texto son limitadas y, por lo tanto, no están acorde con lo que se esperaría para estudiantes de este nivel en lo que se refiere a la manera de com- 
prender y extraer información de un texto académico.

En relación con la generación de conocimiento, los docentes no solo presentan problemas serios de estrategias para realizar una clase organizada y que ayude a transformar la escuela, sino que evidencian dificultades en la adecuación de sus clases a las pautas requeridas, para la transformación del proceso de enseñanza en la escuela.

\section{Conclusiones}

La no organización de la información y el no cambiar sus estrategias de aprendizaje son los obstáculos iniciales con los que se enfrentan los docentes para lograr la administración de la clase en la era de la información, evidenciándose: Los estudiantes poco comparten diferentes clases de textos de un mismo tema y a veces hay trabajo colaborativo con las lecturas de los textos donde hay escasas conclusiones individuales acerca de lo socializado y trabajado colectivamente; además los estudiantes casi nunca siguen una guía entregada por el profesor.

Por otro lado los estudiantes se organizan ellos en grupos utilizando las TIC, no guiados por el profesor, para la producción y aplicación del conocimiento, ellos muy poco utilizan las TIC para almacenar, recuperar y distribuir la información de los textos que leen en clase; además casi siempre presentan en la clase resultados escritos de sus investigaciones, pero no los socializan.

El profesor casi nunca guía a los estudiantes a que lean los textos de su disciplina, para que los apliquen en contexto, él sólo guía a los estudiantes a que lean los textos de su disciplina. Los estudiantes responden a las evaluaciones de su clase en forma mecánica (Conocimiento Tácito); ellos son conscientes de las respuestas en las evaluaciones de su clase (Conocimiento Implícito).

\section{REFERENCIAS.}

Christensen, Crist Roland. (1991). El maestro de la discusión en acción: preguntar, escuchar y responder. Publicación de este documento en EDUTEKA: Mayo 01 de 2011.

Delors, Jacques. et. al. (1996) La Educación encierra un tesoro. Informe a la UNESCO de la Comisión Internacional sobre la Educación para el Siglo XXI. Ediciones UNESCO. París. PP 17.

Díaz Barriga, Frida. (2003). Cognición situada y estrategias para el aprendizaje significativo. Revista Electrónica de Investigación Educativa, 5 (2). Consultado 30 de junio de 2008: http: / / redie. ens.uabc.mx/vol5no2/ contenido-arceo.html

Díaz Barriga, Frida. (2005) HERNÁNDEZ ROJAS, Gerardo. Estrategias docentes para un aprendizaje significativo. McGraw Hill. México. Capítulo 5.

Domínguez Merlano, Eulises. (2009). Las TIC como apoyo al desarrollo de los procesos de pensamiento y la construcción activa de conocimientos. Revista Zona Próxima. Universidad del Norte.

Marzal Garcia- Quismondo, M. A. et al. (2003). La sociedad del Conocimiento: educar para la información y el saber. II Congreso Internacional de Sociedad de la Información y el Conocimiento. Universidad Pontificia de Salamanca. McGraww Hill. Madrid.

Monereo, C. et al. (1994) Estrategias de Enseñanza y aprendizaje. Formación del profesorado y aplicación en la escuela. Graó. Barcelona.

Morin, E. (2000) Los siete saberes necesarios para la educación del futuro. Nueva Visión. Buenos Aires.

Moursund, David. (1999). Aprendizaje Basado en Proyectos Usando tecnología de la información. Quipus. México

Russell, Bertrand. (1999). Sociedad humana; ética y política, Barcelona. Altalaya.

Senge, Peter M. (1994). La Quinta Disciplina. Ed. Granica. España. 